Original Research Paper

\title{
Interdisciplinary Format of the New Master's Program "Popular Science Journalism" at Saint Petersburg State University (Russia)
}

\author{
Yuliya B. Balashova \\ Saint Petersburg State University, Saint Petersburg, Russia
}

Article history

Received: 17-08-2016

Revised: 16-12-2016

Accepted: 19-12-2016

Email: ubalash@gmail.com

\begin{abstract}
The article discusses the new Master's program "Popular science journalism", which started two yeas ago at Saint Petersburg State University, Russia. In 2016 the first students graduated from this program. Together with Moscow State University St. Petersburg University is in the top of Russian universities. The author of this article is the creator, developer and head of the designated program. Currently there is a demand for the science communication development in Russia. The purpose of this article is to describe the structure, content and audience of the "Popular science journalism" Master's program. Modern knowledge tendency to interdisciplinary, convergence should be implemented not only in science, but also in the field of education. Interdisciplinary format of the "Popular science journalism" program is laid down at the conceptual level and in the curriculum. The article aims to show productivity of the interdisciplinary educational programs, combined into modules.
\end{abstract}

Keywords: Master's Program, Popular Science Journalism, Science Communications

\section{Introduction}

The task of promoting science is an important social mission of modern journalism. "Science with and for society" establishes communication between the separated areas of elitist scientific and social sphere. On the way of mastering scientific knowledge mass audience requires a mediator. In the process of scientific communications, the figure of communicator is more important than even in politics, as politicians themselves must be able to act in the public sphere, including contact with press. In terms of communication theory, it is difficult to find some other field of public life, where the communicant would play such a significant role. Reduction of communication with the public can have catastrophic implications for the science itself and for the society either.

At the present time an interest to scientific problematic increased in Russian media. Scientific subjects are actively developing in the printed press and electronic media, new popular science journals have been created. For the first time over a long period in Russia media take an interest in scientific issues.

Training science journalists is an objective need for the state, society, science and media themselves. Russian media market demands science journalists.
However, until recent times the science journalists were practically not trained.

In a situation of internal competition between Master's programs it is necessary to form a metaprogram, principally based on an interdisciplinary approach. The new "Popular science journalism" Master's program has become such a program, which interdisciplinary at the conceptual level and in terms of implementation. It was designed by the author of this article and implemented two years ago at the School of Journalism and Mass Communications, Saint Petersburg State University. Its concept is determined by the requirements of the moment: a pressing social demand to improve scientific picture of the world in the public mind and audience educating.

In the West, scientific journalists are trained at the best universities. American, British science journalists form the elite of journalistic profession, precisely because they are able to understand and present objectively complex issues. In this case, these kinds of Master's programs should be specialized and at the same time-within the selected profile-by of interdisciplinary nature. A good example of Master's degree program in earth and environmental science journalism represents Columbia University (USA). Such programs are 
designed as cross-cutting, with the participation of the journalism schools. In Russia, there is a demand for scientific journalists with universality degree. This correlation allows reconsidering well-known thesis that for Russian journalism education Western European analogues are more important than American ones (Morrison, 1997).

In Russia, the process of scientific knowledge promotion was associated with the development of the audience consciousness, based on knowledge as such. Intrinsically, popularization techniques and methods are sufficiently invariant. Their mastery should be superimposed on some scientific base. From these premises students may have quite different basic education: philological, medical, physical and so on. For the "Popular science journalism" Master's program natural scientists and experts in humanities, physics and poetry are equally important, that follows from its conception. The student audience of this way is universal.

Thus, the purpose of the new Master's program "Popular Science Journalism" is to educate universal science journalists with the general scientific theoretical base and practical skill of creating scientific media texts for the different types of media.

Objectives of the Master's program are: (a) generate comprehensive knowledge about science theory and history in terms of science convergence in the undergraduates; (b) create objectified ideas in the undergraduates concerning the main channels and mechanisms of science popularization from the standpoint of both history and modernity, based on the experience of both Russian and foreign media; (c) generate the undergraduates' practical skill of creating scientific and educational media texts.

Promotion of the project started a few years before it is realization. It happened on several fronts. Firstly, it was publicly introduced in the format of press conferences ("Science-lunch"). Secondly, publications in the federal and regional Russian media were prepared. Third, professional orientation of the students was conducted (as a part of Open Days and special course). Fourth, it has been an interaction with other departments within the university (Department of Physics, Smolny Faculty of Liberal Arts and Sciences).

\section{Methods and Methodology}

Universal scientific methodology can and should realize itself through the institute of education. Of course, we are talking about university education. This idea is expressed in the classical works about the philosophy of education (Jaspers, 2006).

Therefore, the Western modern knowledge model is based on the separation of science and art (Bynum, 2013). Max Weber wrote: "In our time, the internal situation, in contrast to the organization of science as a vocation, is first of all conditioned by the facts that science has entered a phase of specialization previously unknown and that this will forever remain the case" (Weber, 1991).

In such logocentric country, as Russia, the dichotomy of science vs. art is not so relevant. The very type of national consciousness tends to traditionalism and syncretism. In addition, Russia does not have the historical preconditions for the formation of narrow specialization. One of the most significant cultural reasons is as follows. Compared with the Western Europe, classical hierarchy (socio-cultural, sociopolitical) was not developed in Russia.

This aspiration to universalism is reflected in Russian education. Western practice of organizing classical universities as state within a state did not fully match the realities of Russian life. When, at the beginning of the twentieth century, a national high school model in Russia has established, it was based on the idea of general (not special) education (Balashova, 2007). In modern Russian scientific environment evaluative attitude towards humanitarian knowledge has developed, as opposed to natural science. Meanwhile, the idea of the commonwealth of sciences is central to the entire tradition of the national popular science journalism. In the classic Russian "thick" journals the departments of science and literature were mixed. Approach to the understanding of scientific knowledge as universal knowledge is typical to the classical Russian popular science journal.

Another reason is that Russian science has never been separated from the public life (Lazarevich, 1981). Russian universities, as well as the whole system of education being based on the German model, never aspired to be a "state within a state". In the aspect of interaction: Science-society, the biography of Dmitry Mendeleev is representative. A recognized scientist, ruler of the minds of young people studying in the $1880 \mathrm{~s}$, Mendeleev acted as a journalist and as a public figure.

In Russia, even methodological schools, maintained themselves through the journalistic discourse Russian mythological school positioned itself on the way of journal controversy. Russian formalism school, laying the foundation for accurate literary criticism, also tended to various forms of publicity. It is also significant that a unique socio-cultural type as the intelligentsia formed in Russia. The basic quality of the Russian intelligentsia is realization of the moral obligation to the society.

Traditionally, Russian science was public-oriented. Historical and typological model of scientific and popular press in Russia is based on a multidisciplinary approach, uniting science and art. In Soviet times, the system of scientific popularization was provided at a high level and operated very effectively. Soviet scientists themselves were involved in the activities of scientific popularization. Nevertheless, socio-historical transformations have led to the fact that Western 
researchers and Western science appeared to be more open to society than is the case in modern Russia. The basic pedagogical method that was used in developing the program is a project method.

\section{Discussion of the Research Outcomes}

Training of students faces a number of serious problems. The main problem is universal scientific nature: Different fields of knowledge are highly fragmented among themselves. There is a deficit of fundamental scientific trainings in the university programs. In humanitarian educational cycle such reductionism is due to two main reasons: (1) the rapid development of non-classical and applied humanities majors (such as tourism, advertising and others), (2) the overall reduction of hours devoted to humanitarian disciplines of the federal component of the curriculum.

If we talk about journalism education, the professional community is increasingly leaning toward the position that strengthening scientific training of future journalists is actually necessary. In this way it is really necessary to take into account one of the main features of Russian media education in contradistinction to the West. In the Western universities and Schools of journalism (first of all-in the USA) the major part of teaching hours and classes are allocated to the formation students' skills to work with information and make reports for the different type of media. Whereas in training future journalists in Russia an impact to their ability to form an opinion is dominant. In other words,-in accordance with the well-known in Russia expression-if the "poet in Russia is more than a poet", the journalist is not only an organizer of communication.

The purpose of the Master's program "Popular science journalism" defines wide approach to its formation. The developed program is not only interdisciplinary, but also interdepartmental. The existing profiles of Master's programs are taken as a point of reference here rather than the department and faculty. The main thrust of the program is humanitarian.

The main areas of "Popular science journalism" Master's program are: (a) general scientific, (b) history, theory and practice of scientific popularization, (c) poetics of scientific and educational media text.

The main courses of the curriculum are as follows: "Introduction to Methodology and History of Science", "Modern Natural Science", "History of Popular Science Journalism", "Contemporary Scientific and Educational Film: Types and Genres", "Popularization of Science in Print Media", "Popularization of Science in AudioVisual Mass Media", "Travelogue Discourse", "Creative Studios", "Environmental Journalism".

What are the learning objectives within the framework of the Master's program?

\section{Task 1}

Graduates should be worthy of a general scientific level, which itself serves as a natural barrier to pseudoscientific knowledge. Basic discipline "Introduction to the Methodology and History of Science" opens Master's degree program curriculum. It is aimed at establishing a common understanding of the scientific process in its unity: Diachronic and theoretical. The idea of sciences convergence, scientific revolutions, with regard to science ethics, the humanitarian inspection in the field of high technologies has been put as a methodological criterion. The following major historical periods of the scientific picture of the world formation are distinguished: Antiquity, the Renaissance, classical science and technique of modern times (18-19th centuries), non-classical science (end of the 19th century-the first half of the 20th century).

Discipline "History of Popular Science Journalism" promotes addition and deepening of the given coordinate system. In the framework of science popularization history it is considered in conjunction with the development of science and socio-cultural situation. This discipline is designed to reveal the historical and typological models of domestic popular science journalism, which can be applied in the present. Within the course "History of Popular Science Journalism" students get the following task. They should create a popular science journal. More precisely, they should form specific journal model, its content and design. Their projects are posted on the faculty website. In addition, within this historical discipline students write a paper: "Course research paper in history of popular science journalism: The 18-20th centuries".

The idea of convergence of humanitarian and natural sciences is carried among the various disciplines of the curriculum. Natural science direction outputs this master program on the wide level of interaction.

\section{Task 2}

The program is called "Popular Science Journalism", not just "Science journalism". It is designed to neutralize the possible disparity between the different areas of knowledge. The program emphasizes adaptation of scientific information for a mass audience through the media, movie, literature; and, if we consider more specifically, for example, through travelogues. This feature allows standing out from the alternative Master's programs. All disciplines are focused on the practical application of knowledge. "Creative studios" are totally practice-oriented. They are divided into two modules: Science popularization in print media and audio-visual mass media (Zinsser, 2006; Graff and Birkenstein, 2014). Within the first module students write popular science articles and reviews for the corporative popular science journal "Saint Petersburg University". In the 
second way they prepare the script and an application for a non-fiction television program.

During the last semester, students learn discipline "Poetics and stylistics of popular science text", designed to summarize the obtained theoretical and practical skills. In this context the main components of poetics and style of the popular science text are considered. In the aspect of poetics these are the basic journalistic genres of the popular scientific text: news, popular scientific articles, interviews, reports. Also architectonic and composition, headline and lead, the pyramidal structure of the popular science media text are studied. In the aspect of the language a major focus of interest is the technology of adapting scientific statements to a mass audience; the ways of working with conceptual apparatus, sources and references; correct citation; editorial work on the text. All of these techniques are considered both in terms of media criticism-critical analysis of journalistic text and at the same time-creation of own media texts.

Within the framework of purely practical disciplines the cycle accentuated the following aspects of the scientific and educational media texts: its code multiplicity, intention of hobbies and entertainment at the same time, interaction of verbal and nonverbal components. One of the most important skills, process formation of which is given special attention, is the ability to increase information occasions. The key problem of science coverage lies in the fact that the agenda created in the scientific community requires serious processing to become a media message.

\section{Task 3}

Unfortunately, the educational and research institutions objectively lack the tools to struggle against pseudo-science. Mission of this Master's program graduates is also to carry out this kind of activity in the terms of specific journalistic actions (in the way of investigative journalism, the formation of adequate public opinion). Countering pseudo-science in the humanitarian sphere is no less important than in the natural sciences field. Different fields of knowledge converge at this position, but differ in their constitutive role in terms of the formation of ideas about the past and the future. Compensatory function of scientific popularization also has considerable potential. It allows expressing that it is difficult to talk under the rigorous scientific discourse.

Scientific and popular press is an intellectual resource, which should satisfy the need for knowledge about the world. There is a hypothesis about a half-life of knowledgethe time period after completion of training, during which half of original assimilation of information is lost.

Decline in the prestige of science, its chronic underfunding (especially the humanities), the disunity of the scientific community and its poor mediatization-all these factors contribute to a crisis situation in which the Russian science has occurred now. Scandals involving science create the typical information science media landscape. Media gladly tell the stories about counterfeit dissertations, an endless series of sensational scientific discoveries, finally, practical advices a la "British scientists have found out". Daily academic life: Conferences, expeditions, defense of dissertations, as is commonly believed, does not create information occasions and mostly remains outside the media coverage. The ability to pedal the information occasion, bring it closer to the needs of the audience requires professional skill (Donald, 2013).

\section{Conclusion}

In the mid-eighties in Russia the cultural and commodity exchange with the West repeatedly amplified being followed by expansion of ideology of an affluent society. The interests of a consumer society in general and currently established in Russia in particular are focused on glamour and tourism, while popular science journalism generates appropriate values of the audience. Worthy science popularization should be able to observe the correct proportion between entertainment and cognitive aspects. The primary audience of the popular scientific press is quite elitist.

The graduates of the Master's program should have some kind of universal cognitive base. In addition, they should be able to pedal scientific information occasions, to bring them closer to the audience. Meanwhile, the controversy in the public space towards the science popularization is centred on those issues that have been long known. The issue whether journalists could popularize science or not is actively discussed in public. A positive answer to this question is well known. In Soviet times, the objective of which was to raise the level of the mass audience to the scientific one, science was successfully popularized by the scientists themselves and by journalists. A similar situation exists in the Western press. Actual master program is developing in this line.

Graduates should be able to act in two main directions. Firstly, they should be able to mediatizate science itself. In this case, their focus is to advance scientific knowledge, revealing approach to building modern scholarly communication. In the second case, they would think about audience and developing its picture of the world. In Russia, scientific education always solved these two problems.

In our view, a modular approach is the principle of Master's programs adequate formation in the framework of structural association (faculty, institute). Science itself and "Science journalism" represented by the developed Master's program are elite areas. At the end of the first year the number of students reduced by one third: from 
nine to six. This happened despite the fact that these students at admission had the highest score. The reason of this situation is the difficulty of the program. According to opinion poll among students, they consider that this Master's program profile forms both cognitive and practical experience. In the context of the other journalistic Master's programs at Saint Petersburg State University, this program is close to the number of programs: "Documentary Film: Creativity and Technology", "Historical Journalism", in some part-with the program "Journalism and the Culture of Society". These programs have a lot in common in terms of curriculum. It makes sense to combine them into a single modular unit with a variable part. Such modularity would provide horizontal mobility within the programs.

It is well known that science can be in progress only in the situation of scientific schools and scientific environment existence. Scientific popularization also develops only in the system of different promotional formats and integrated marketing communications. Therefore, the considered master program is working closely with the club of science journalists "Science Matrix". It has been working in St. Petersburg for more than ten years and organizes press conferences with leading scientists.

The main positive expected outcome of this program is as follows. Graduates of the Master's program will certainly be in demand. We already have an employment offer from the press service of the academic institutions and popular science journals. It is important that as a result of students' research, journalistic and teaching practice they would provide jobs at the stage of Master's degree. Graduates of the Master's program have to fill the vacant segment of science journalists. It is very important that at the end of the magistracy, they will work not in journalism in general, but more specificallyin scientific journalism.

Finally, there is one paradox. In Russia, scientific popularization cannot be unpopular. It follows from the traditions and peculiarities of national identity.

\section{Acknowledgment}

The authors gratefully appreciate the support of the Russian Humanitarian Scientific Fund.

\section{Funding Information}

The article has been prepared with the financial support of the Russian Humanitarian Scientific Fund (RHSF). The project No. 16-03-50128.

\section{Ethics}

This article is original and contains unpublished material. The authors confirm that there are no ethical issues involved.

\section{References}

Balashova, Y., 2007. Silver Age school journalism. St. Petersburg State University Press, St. Petersburg.

Bynum, W.F., 2013. A Little History of Science. 1st Edn., Yale University Press, New Haven, ISBN-10: 0300197136, pp: 263.

Donald, G., 2013. The Accidental Scientist: The Role of Chance and Luck in Scientific Discovery. 1st Edn., Michael OMara, London, ISBN-10: 1782430997, pp: 236.

Graff, G. and C. Birkenstein 2014. "They Say / I Say": The Moves That Matter in Academic Writing. 3rd Edn., W. W. Norton, New York, ISBN-10: 039393585X, pp: 335 .

Jaspers, K., 2006. The Idea of University. Belarus State University Press, Minsk.

Lazarevich, E., 1981. Popularization of science in Russia. Moscow State University Press, Moscow.

Morrison, J., 1997. The changing model of Russian media and journalism education. Journalism Mass Commun. Educat., 52: 26-34. DOI: $10.1177 / 107769589705200304$

Weber, M., 1990. Science as a Vocation. In: Selected Works, Weber, M. (Ed.), Progress, Moscow, pp: 707-735.

Zinsser, W.K., 2006. On Writing Well: The Classic Guide to Writing Nonfiction. 7th Edn., HarperCollins, New York, ISBN-10: 141775057X, pp: 321. 